\title{
mssaico
}

\section{Ditadura militar e} resistência legal: as memórias de Mércia

\section{Albuquerque através do seu} diário (1973)

\author{
Angela Moreira \\ Domingues da Silva ${ }^{1}$
}

\section{Resumo:}

O presente artigo tem como objetivo analisar o diário da advogada de presos políticos durante a ditadura militar, Mércia Albuquerque, no ano de 1973 , à luz do debate sobre a memória e seus usos. Acrescenta-se a isso, a possibilidade de analisar a atuação da Justiça Militar através de um enfoque diferenciado dos tradicionais estudos sobre o tribunal militar, uma vez que, através do registro de Mércia, pode-se ter acesso a relatos sobre a estrutura do foro castrense, além dos atores que o compõem, que não estão presentes na produção documental própria do tribunal militar em sua dinâmica processual.

Palavras-chave: diário, Ditadura Militar, esquecimento, Justiça Militar, memória

\section{Abstract:}

El presente artículo tiene como objetivo analizar el diario de la abogada de presos políticos durante la dictadura militar, Mércia Albuquerque, en el año de 1973, a través del debate sobre la memoria y sus usos. Acrecentase la posibilidad de analizar la actuación de la Justicia Militar a través de un enfoque diferenciado de los tradicionales estudios sobre el tribunal militar, pues a través del registro de Mércia, puédese tener a relatos sobre la estructura del foro castrense, además de los actores que lo integran y que no están presentes en la producción documental propia del tribunal militar en su dinámica procesal.

\footnotetext{
${ }^{1}$ Doutoranda do Programa de Pós-Graduação em História, Política e Bens Culturais da Fundação Getúlio Vargas (RJ).
} 
Eu trago no rosto

Sulcos profundos.

Que cicatrizes são

De dez anos de luta

Onde está a minha juventude

A beleza de minha mocidade

Procuro e não encontro

Se foram sem que sentisse

Fios de prata enfeitam-me

Marcam a presença do tempo

Injustiças aos estudantes

Intranquilidade ao povo

Mas não envelheço a alma

Pois caminho com a mocidade

Sofro com ela as crueldades

De um poder tacanho e velho.

(Mércia Albuquerque ${ }^{2}$ )

Regimes autoritários, pautados por atos de coerção física e político-ideológica, deixam vastas sequelas nas sociedades que os vivenciaram. Operações como esquecimento, recordação e silêncio são constantes em uma equação que envolve, simultaneamente, sentimentos como vergonha e orgulho, além de questões como sobrevivência e perpetuação. Ao longo de um período de repressão e arbitrariedades, e mesmo durante o rearranjo político-social que se dá após seu término, inúmeros registros são feitos, conscientes ou não, escritos ou não, falados ou não, com o intuito de olvidar experiências traumáticas e ressentimentos, ou mesmo de trazê-las à tona, objetivando um movimento de denúncia e expurgo dos abusos cometidos no passado.

Esta gama de sentimentos redunda no que se convencionou chamar "dever de memória", posto em prática envolvendo questionamento como "para quê lembrar" e/ou "como lembrar". 3 A função social destas indagações contem posicionamentos de cunho político de grupos específicos e se deixa transparecer através de uma relação direta entre Estado e sociedade. Este diálogo, por sua vez, promove sérias disputas, entre forças políticas distintas, pelo poder da memória, ou seja, para instituir opiniões ou normas acerca do que deve ser lembrado ou esquecido. Em regimes democráticos, estas operações não são tão simples, uma vez que não impostas, são debatidas e disputadas.

Existem muitos relatos memorialísticos de pessoas que atuaram politicamente

2 Poema registrado no diário da advogada de presos políticos, Mércia Albuquerque, em 5 de agosto de 1974. Ver <http://www.dhnet.org.br/memoria/mercia/escritos/diario/1974/08_agosto/005.htm> 3 Para maiores informações ver HEYMANN (2007) e ENDERS (1993). 
durante a ditadura militar brasileira (1964-1985) e o movimento de registrar o testemunho dos atores políticos da época não se restringe a um setor único. Militares do palácio e da caserna, militantes da luta armada, políticos, advogados, entre outros grupos, se manifestaram no sentido de escrever sua experiência política ao longo do regime castrense.

Curiosamente, a preocupação com a "memória" sobre o período está declaradamente expressa nestes depoimentos, como podemos observar através de alguns títulos bastante sugestivos: Mulheres, militância e memória, de Elizabeth Ferreira (1996); Memórias do esquecimento: os segredos dos porões da ditadura, de Flávio Tavares (1999); Memória dos vencidos: a vez e a voz dos vencidos, de Hélio Silva (1988); Os anos de chumbo: a memória militar sobre a repressão, organizado por Maria Celina D’Araujo e Celso Castro (1994).

No Brasil, há um debate interessante sobre a questão da memória do período, que reflete esta disputa pela imagem construída sobre os militares e os que atuaram em oposição aos seus governos, pelas reminiscências vindas à tona atualmente:

(...) se venceram a guerra contra as organizações da esquerda revolucionária, foram derrotados na luta pela memória histórica do período. É importante observar que muitos militares se "queixam" justamente de não se ter apresentado uma versão das Forças Armadas sobre a repressão que fosse socialmente acatada como legítima. Se normalmente a história esquecida é a dos vencidos, na questão do combate à guerrilha haveria como que um movimento perceptivo inverso - a história ignorada seria a dos vencedores. Dessa forma, para alguns militares, teria predominado uma situação peculiar em que o vencido se tornou-se o "dono" da história (D’ARAUJO, 1994: 13).

Apesar de este debate sobre a memória acontecer, sobretudo, no período pósditadura militar, acreditamos que algumas fontes históricas, produzidas durante o regime autoritário, como o diário, por exemplo, nos remetem a esta discussão e nos auxiliam na reflexão sobre a época.

A participação feminina em diversas atividades de resistência à ditadura militar tem sido objeto de estudos frequentes, principalmente, no que se refere à sua atuação na luta armada. A categoria profissional dos advogados imprimiu forte ritmo e se constituiu como um dos protagonistas de uma espécie de resistência legal às práticas autoritárias ensejadas pelos governos militares, principalmente por representarem diretamente aqueles que estavam presos, sendo processados, julgados e condenados por agirem em espaços e por motivos considerados ilegais. Uma das maneiras de se compreender como estes defensores

4 O sentido dos termos "Palácio" e "caserna" está intimamente ligado à obra de Martins Filho (1995), acerca dos conflitos políticos governamentais e sua relação com as disputas intramilitares, respectivamente. 
faziam face aos ditames ditatoriais é sistematizar sua atuação, mapeando seus espaços de sociabilidade. Estes profissionais integravam o que Pierre Bourdieu denominou campo jurídico ${ }^{5}$, ou seja, um

Lugar de concorrência pelo monopólio do direito de dizer o direito, que dizer, a boa distribuição (nomos) ou a boa ordem, na qual se defrontam agentes investidos de competência ao mesmo tempo social e técnica que consiste essencialmente na capacidade reconhecida de interpretar (de maneira mais ou menos livre ou autorizada) um corpus de textos que consagram a visão legítima, justa, do mundo social (BOURDIEU, 1989: 212).

A utilização desta fonte traz fôlego a estudos que estão sendo elaborados sobre a atuação da Justiça Militar no julgamento de crimes contra a segurança nacional, durante a ditadura militar brasileira. Em 1965, com a publicação do Ato Institucional № 2, durante o governo do presidente general castelo Branco, os julgamentos dos chamados "crimes contra a segurança nacional" foram transferidos para a Justiça Militar, envolvendo suas duas instâncias, Auditorias Militares e Superior Tribunal Militar.

Recorrer a documentos como processos e matérias jornalísticas nos permite recuperar as experiências dos atores políticos envolvidos na atuação do tribunal militar, proporcionando a colheita de indícios que retratem seu comportamento e posicionamento formais frente às instituições jurídicas. Todavia, estas fontes históricas não nos propiciam alcançar um outro lado da rotina destes profissionais, que lidavam constantemente com ameaças e inseguranças. Suas impressões, indignações e sentimentos estavam presentes, porém não se mostravam tão explicitamente ao longo das "Razões de Defesa", por exemplo.

Mércia Albuquerque foi uma importante advogada de presos políticos, atuante no estado de Pernambuco. Formou-se na Faculdade de Direito do Recife, em 1961, e poucos anos depois já estava atuando na defesa de presos políticos. Em 1964, enquanto ainda exercia a atividade de estagiária, Mércia se deparou com um caso que mais tarde seria considerado emblemático da repressão militar ao comunismo. Assumiu a defesa de Gregório Bezerra, líder comunista preso e arrastado por um carro, pelo bairro de Casa Forte, na capital pernambucana. Sua atuação foi tão incisiva, que desde o primeiro ano de ditadura militar, Mércia foi presa doze vezes.

5 Para compreender melhor a atuação político-institucional da Justiça Militar, aproveitaremos esta noção de campo jurídico, e além dos advogados de presos políticos, consideramos como pertencentes a esta rede de sociabilidades os componentes do tribunal militar como um todo: juízes, ministros, auditores, promotores e advogados de ofício e réus.

6 Geralmente, este tema fica restrito aos meios militares e aos profissionais e acadêmicos da área de Direito, mas importantes obras na área das Ciências Sociais, em especial da História vêm sendo produzidas. Ver D'ARAUJO (2006), LEMOS (2004a; 2004b); MACIEL (2003); PEREIRA (2005), SILVA (2007), ZAVERUCHA (2004). 
Durante pelo menos cinco anos intercalados (1968, 1972, 1973, 1974 e 1979) Mércia escreveu em seu diário, relatando sua prática profissional e o relacionamento com seus clientes, amigos e família. ${ }^{7}$ Escolhemos comentar sua produção ao longo de 1973, pois a partir deste ano a advogada se dedicou a escrever no seu diário com mais frequência.

Esta fonte histórica não se enquadra no rol de produções que marcam o movimento de "dever de memória" citado anteriormente, uma vez que foi produzido durante a ditadura militar. No entanto, pode ser entendido através desta chave, uma vez que permite acesso a fatos ainda tratados de forma delicada na relação Estado-sociedade durante o período de redemocratização até os dias atuais, como por exemplo, a prática de tortura e desaparecimentos cometidos durante a ditadura militar.

Vale ressaltar o cuidado que se deve ter em empregar tal expressão e todo o arcabouço conceitual que ela encerra para tratar do período da ditadura militar no Brasil. Como salienta Heymann, no Brasil tal expressão não faz "parte do léxico das políticas públicas voltadas para a gestão de passados sensíveis" (2007:17), tratados de forma mais peculiar como "resgate de memória" ou dever de justiça", pelos grupos que reivindicam "acesso ao passado". 8

Uma importante característica desta fonte é o fato de nos proporcionar o acesso ao que podemos considerar serem os bastidores da intrincada relação entre a advogada e os presos políticos que defendeu, sua família, os órgãos de segurança e, finalmente, a os integrantes da estrutura da Justiça Militar. Por si só, o diário de Mércia Albuquerque já apresenta um valor inestimável para compreendermos um período no qual a garantia e o respeito aos direitos humanos não estavam assegurados. Seus registros pessoais, somados à outras fontes, como as peças dos processos, a legislação e relatos orais possibilitam uma preciosa e original leitura sobre o período.

A princípio, a produção do diário pode ser analisada com o objetivo claro de "dar ao eu um corpo de palavra cujo contorno será a história do autor" (REMÉDIOS, 1996: 2). Esta fonte se descortina em inúmeras possibilidades de investigação do período da ditadura militar. Temas como a atuação dos advogados de presos políticos, enquanto promotores de uma resistência legal ao regime, a participação feminina neste movimento de oposição, além do funcionamento da Justiça Militar no período podem ser alcançados através desta fonte. A investigação deste último tema, particularmente, ganha um toque especial através do diário

7 A família de Mércia repassou seu acervo para a DHnet - Rede de Direitos Humanos e para a Rede Estadual de Direitos Humanos-RN, que se encontra parcialmente disponível no site corresponde à produção integral de Mércia. <http://www.dhnet.org.br/memoria/mercia/>. Pode-se acessar importantes documentos produzidos pela advogada ao longo de sua atuação profissional, como seu diário, trechos dos processos nos quais atuou, além de correspondência trocada com colegas de profissão como Heráclito Sobral Pinto e Modesto da Silveira.

8 Heymann faz uma importante discussão do rearranjo político-social que se fez durante a redemocratização, e de como as decisões políticas da época ainda incidem no debate sobre memória acerca da ditadura no Brasil. 
de Mércia.

O diário pode ser visto, então, como fonte que permite acesso a questões do "interior" da repressão, como por exemplo a prática da tortura pelos órgãos de segurança, através da ótica de um ator - o advogado de defesa -, que pode ser pensado como "mediador" entre todos os envolvidos no funcionamento da Justiça Militar, dando margem ainda para pensar a instituição em sua relação com os órgãos de repressão.

Este documento nos propicia conhecer os meandros e o funcionamento da Justiça Militar por um outro ângulo: através da intimidade de quem nela atuou, despojada das formalidades que compunham a rotina e a dinâmica processual:

Fiquei perplexa com o que aconteceu com o Dr. José Bolivar Regis, auditor da $7^{\circ}$ Circunscrição Judiciária Militar.

O Dr. Jerson Maciel Neto, alegava excesso de prazo (prisão preventiva) do acusado Bento de Tal, então o auditor aparteou dizendo: "É doutor, esse negócio é só mesmo no papel, não é para se cumprir". Abismado diz: "Dr. Auditor, V. Exa. Atentou para gravidade da sua afirmação?". Ao que o auditor começou a rir, deixando transparecer que o problema vinha de cima.

E orientou o conselho, erradamente, inclusive sem usar os termos técnicos jurídicos. Tá bom.

Diferentemente da autobiografia, o diário íntimo reflete um pacto do autor consigo próprio, introspectivo, "pois há menor distância temporal e espacial entre o eu, o vivido e o registro desse vivido pela escrita" (REMÉDIOS, 1996: 5). Apesar de estabelecer um ponto de contato com o leitor ao falar do eu, o relato confessional de certa forma o excluí. Ainda assim, "esse tipo de produção, além de fonte histórica e experimento literário, é em si mesmo parte da história e da construção do sujeito e de sua biografia" (D’ARAÚJO, 1996: 1).

Segundo Darío Villanueva, ao se dedicar à atividade de narrar "o homem enuncia continuamente sequências de acontecimentos, pode explicar seu passado e seu presente, aventurando-se pelo futuro; pode justificar, responsabilizar, ser verdadeiro ou mentir (...)"

9 Maciel (2003) ressalta a existência do que chamou de repressão judicial, que obedecia a duas fases distintas: 1. Sequestro do militante por algum órgão de segurança, interrogado sob tortura e mantido incomunicável durante a formação do Inquérito Policial Militar (IPM); 2. Fase judicial, quando era formalizado o inquérito e a Justiça Militar era comunicada da prisão. Os IPMs - base para a formação de denúncia dos presos -, na maioria das vezes, eram constituídos de informações obtidas nas sedes das agências de segurança, onde o preso era submetido a coação física no momento do depoimento. Assim, a peça fundamental que sustentaria a abertura do processo judicial já nascia como consequência de uma prática arbitrária.

108 de setembro de 1973. 
(apud REMÉDIOS, 1996: 2). Ao longo das suas exposições, percebemos que os escritos da advogada são dotados de uma temporalidade própria, a princípio organizada cronologicamente, através da vinculação dos acontecimentos a datas precisas, mas que se revela um pouco mais sofisticada, quando observamos que a descrição dos seus dias estava condicionada ao registro das prisões e dos atentados aos seus cliente e amigos.

É em meio a estes fatos, protagonistas nos seus escritos e rotineiros na sua atividade profissional, que encontramos a Mércia esposa e mãe:

Fui com Jerson visitar os presos de Itamaracá. Conversei com todos, e sofreu com eles. Faço o que posso, e às vezes até mesmo o que não posso. $\mathrm{A}$ morte de Ramires continua envolvido em mistério, até mesmo o pessoal da segurança não sabe informar, pois tudo indica que morreu com outra identidade. Tenho recebido apelos constantes para aceitar a defesa de Juarez, é difícil pois Boris vai se julgar preterido, e ganharei novo inimigo. Estou satisfeita com Aradin (seu filho).

Pode-se afirmar, portanto, que Mércia ao periodizar à sua forma o mundo que a cerca, cria um "tempo próprio" e no mesmo passo, um sentido para a sua vida. Percebe-se que a construção dessas distintas temporalidades, que convivem simultaneamente, possibilitam uma organização e um rearranjo do meio em que vive, em que coexistem sentimentos de satisfação, como se observa ao narrar fatos referentes ao filho, e de sofrimento, como se nota na descrição de alguns componentes das instituições militares.

O exercício de escrever em seu diário pode, simplesmente, ser visto como um ato de expurgo, ao narrar acontecimentos caracteristicamente adversos que perpassavam sua vida pessoal e profissional: "Hoje, foi posto em liberdade, o mecânico Heráclito. Este homem foi torturadíssimo, estava totalmente inchado. Consegui libertá-lo. $\mathrm{O}$ inquérito foi arquivado. Creio que esse homem não vai viver mais uma ano.." ${ }^{13}$ Algumas passagens do seu diário, no entanto, revelam um claro tom de desabafo de uma profissional que foi se transformando pessoalmente, à medida que exercia seu ofício:

O mundo seria bem melhor se os homens não se preocupassem tanto com o futuro.

Não sinto nenhum conflito, já houve épocas que tinha um estado

11 Como saliente Paul Ricoeur (2000), uma das dimensões fundamentais do trabalho de memória é o simples ato de datar, não necessariamente recorrendo à data numerada, mas à acontecimentos que façam sentido na intrincada rede temporal de cada indivíduo.

1215 de dezembro de 1973.

131 de março de 1973 


\section{Ditadura militar e resistência legal:}

as memórias de Mércia Albuquerque através do seu diário (1973)

de conflito permanente. Era quando existia dentro de mim uma incerteza com relação a mim mesma. Eu vacilaria, eu temia porque pensava no amanhã e também porque não me encontrava.

Da mesma forma que temos acesso aos comentários e informações sobre o funcionamento da Justiça Militar, podemos observar que a autora dedica boa parte das suas reflexões a tratar da repressão praticada pelos militares e pelos integrantes dos órgãos de segurança. O espaço íntimo e privado do seu diário permitia-a tecer críticas severas à atuação arbitrária destes órgãos, que jamais poderiam ser manifestadas publicamente. $O$ tom de repreensão e censura, aliados a uma ironia perspicaz, podem ser lidos em diversas passagens, como as que seguem:

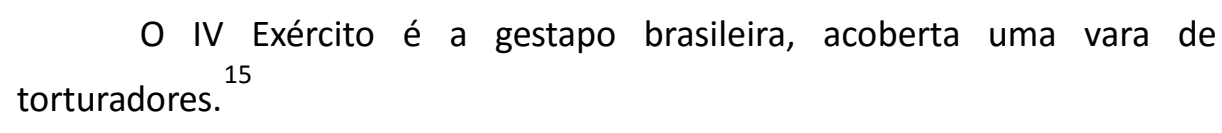

O IV Exército é a gestapo brasileira, acoberta uma vara de torturadores.

Não sei se o DOI é um hospício. Ou a caverna de Ali Babá? ${ }^{16}$

Depto de recuperação, presos. O DOI agora mudou de nome? Daqui há pouco, receberá o nome de Hospital psiquiátrico.

No meu entender, os componentes do DOI, são portadores de "síndrome de deterioração". Homens maus, que vibram com a morte, que a violência abafa as angústias de que são portadores. Explicou os atos anormais como amor à pátria.

Quem ama constrói, amor é vida, amor verdadeiro.

Esses elementos, são necrófilos, amam a morte e no dizer de Erich Fromm "O necrófilo pretende regressar às trevas do útero, são orientados para o passado".

O necrófilo é obsessivo e pedante. São pegajosos, cheira a mofo e lembram fezes. Eu os conheço e sempre sinto vontade de vomitar quando os encontro, porque estão úmidos de sangue. ${ }^{18}$

Em determinados momentos, Mércia suaviza o conteúdo denso do seu diário

14 Idem.

1517 de setembro de 1973

1620 de setembro de 1973.

1723 de setembro de 1973.

1813 de dezembro de 1973. 
apresentando um viés cômico nos seus escritos:

Mamãe me escreveu muito preocupada com a minha saúde.

Essa velha é uma jóia, conseguiu superar todas as feiuras da vida com uma coragem espetacular.

Hoje, com sessenta anos, estuda, trabalha, faz política, e é um bocado encrenqueira. Não se lamenta, é dominadora, é capaz de ir às últimas consequências para alcançar um objetivo.

Em contrapartida, temas como (in)justiça, prisão, tortura e morte muitas vezes são retratados através de poemas ou mesmo de indagações de cunho existencialista:

Vi No silêncio da tarde, Quando o sol desfalecia Os restos dele surgirem Não se sabia o que houve Braços e pernas quebrados A carne em putrefação Oito dias se fazia Da sua detenção Todos os dentes partidos, Escalpelado também Não havia sinal de balas Havia apenas uma verdade Que morrerá de pancadas, Pau de Arara, telefones Pontapés e cacetadas Num massacre, odiento Sem defesa e sem culpa Subtraíram-Ihe dos vivos. ${ }^{20}$

Suas lembranças sempre aparecem vinculados a alguém ou a um fato vivido por outra pessoa, o que nos remete às considerações de Maurice Halbwachs sobre memória individual e memória coletiva (1990). Para o autor, a memória individual não passa de um ponto de vista, de um ângulo de visão da memória coletiva, que de tão internalizada pelo indivíduo parece uma construção única. Analisando a produção da advogada a partir desta concepção, arrisca-se a dizer que a memória de Mércia é única e plural ao mesmo tempo, pois é marcada por uma temporalidade e por um sentido próprios, que servem como espelho, ao mesmo tempo, de eventos que envolvem os atores que com ela se relacionavam e da conjuntura social na qual atuava.

Pelo fato de lidar com temporalidades múltiplas, sempre como uma elaboração do presente, evocando o passado e projetando o futuro, pode-se afirmar que a memória é plural. Fazendo uma leitura do diário de Mércia, através dos preceitos halbwachianos, encontramos em suas reflexões sobre o ano de 1973, que a esta altura já se findava, uma visualização quase que didática, de como o indivíduo brinca com noções temporais distintas e faz projeções de e para si, que inevitavelmente implicam o seu convívio em sociedade:

1928 de março de 1973.

2025 de dezembro de 1973. 
Amanhã encerra-se 1973. Quantas coisas não tive tempo de fazer, Quantas coisas não me deixaram fazer, mas haverei de continuar firme, enquanto viver tentando cumprir as tarefas de que fui incumbida. A vida é assim mesmo, elaboramos um modelo mental do que deveria ser e calcado os pés na realidade do ser, convivemos com o passar dos dias.

O consolo é que este olhar constante numa linha do horizonte bem distante e o caminhar ininterrupto em direção dela, se constitui a mola mestra do progresso da humanidade.

Eu sei que sou, eu sei o que quero, eu conheço razoavelmente o homem, nunca perdi oportunidade em aprender. ${ }^{21}$ [Grifo nosso]

Eu não vi o tempo passar, empenhada na luta pela liberdade, pela paz dos que me confiaram uma tarefa.

Muita coisa deixou de ser feita, ou melhor, muitos objetivos não foram alcançados, mas continuarei tentando em $1974 .^{22}$

Além de registrar fatos vinculados à sua atividade profissional, Mércia demonstrava preocupações outras, que não se restringiam à defesa e aos cuidados dos seus clientes, mas que refletem inquietação com questões de cunho social:

Os canaviais em diferentes áreas do estado estão sendo incendiados. A safra de cana este ano supera as expectativas, ultrapassa as quotas das usinas, logo os fornecedores de cana têm interesse que haja incêndio, tem prioridade para moer as canas, não pagam $13^{\circ}$ mês, e ainda se furtam a compromissos bancários.

Lamentavelmente, camponeses vão à cadeia, para pagarem crimes que não cometeram. Além de serem roubados pelos latifundiários, são arrastados ao cárcere pelos crimes que deveriam ter cometido. Em que mudaram os homens? As feras continuam as mesmas, devoram o próximo por uma migalha.

Os ventanias serão sempre sacrificados em prol dos potentados, isto ocorreu ontem, hoje e continuará ocorrendo na amanhã. Ocorre aqui, na Europa, Ásia, enfim, onde houver homens haverá misérias.

2130 de dezembro de 1973.

2231 de dezembro de 1973.

23 Dezembro de 1973. 
A forma da escrita de Mércia pode ser considerada um capítulo especial de sua produção. Ao mesclar poesia e prosa, que convivem em vários momentos de forma harmoniosa, a advogada imprime um toque a mais de sensibilidade em um relato, que por sua própria natureza, já nos permite entrar em contato com temas e com uma visão de mundo mais íntima. $\mathrm{O}$ alcance dessa dimensão literária que se pode atribuir ao diária de Mércia, pode ser observado através do fato de ela, por exemplo, fazer da tortura matéria de verso em suas páginas.

A produção de Mércia, de certa forma, humaniza o estudo e a investigação sobre um período delicado da história brasileira e de um tema considerado árduo por todas as características que o cercam, a atuação da Justiça Militar enquanto foro de julgamento de presos políticos. O relato que fazia das vivências cotidianas de sua profissão estão marcadas por uma inteligibilidade distinta daquela que se observa em fontes tradicionais utilizadas no estudo do tribunal militar, uma vez que não está limitado às especificidades institucionais de um modelo de escrita encontrada na linguagem processual, por exemplo.

Trabalhar com diário íntimo enquanto fonte histórica significa pensá-lo enquanto um suporte, que possibilita uma forma de acesso ao passado, de alcance do testemunho de Mércia Albuquerque sobre suas experiências, suas verdades, levando em consideração a fluidez das fronteiras temporais. Ricoeur, ao discorrer sobre a relação entre história e memória, admite que a primeira não tem a capacidade de fazer o que ele chama de "pequeno milagre" da memória, ou seja, não produz o reconhecimento do passado, mas sim promove uma operação de estranhamento perante as verdades daquele que produziu a memória (2000). Partindo desta perspectiva e do princípio de que a memória se constitui como um elemento essencial de identidade, individual ou coletiva, procuramos comentar os escritos da advogada Mércia Albuquerque à luz das concepções sobre memória, inserindoos, por sua vez, no viés de uma discussão maior, sobre as disputas pela memória do regime militar brasileiro.

\section{Bibliografia:}

BOURDIEU, Pierre. O poder simbólico. Lisboa: DIFEL, 1989.

D’ARAUJO, Maria Celina. "O fio da meada no diário de Vargas". Estudos Históricos, Rio de Janeiro, CPDOC/FGV, n. 17, 1996.

D’ARAUJO, Maria Celina; CASTRO Celso; SOARES, Gláucio Ary Dillon (Orgs.). Os anos $e$ chumbo. A memória militar sobre a repressão. Rio de Janeiro: Relume-Dumará, 1994. 
D'ARAUJO, Maria Celina. Justiça Militar, segurança nacional e tribunais de exceção. Trabalho apresentado no 30‥ Encontro Anual da Anpocs, Caxambu, outubro de 2006.

<http://www.cpdoc.fgv.br/projetos/cfa21/arqs/anpocs2006/103.pdf>

Enders, Armelle. "Le lieux de mémoire, dez anos depois", Estudos Históricos, v. 6, n. 11, p. 128-137, 1993.

FERREIRA, Elizabeth F. Xavier. Mulheres, militância e memória : histórias de vida histórias de sobrevivência. Rio de Janeiro: Ed. FGV, 1996.

FERREIRA, Marieta de Moraes. "Diário pessoal, autobiografia e fontes orais: a trajetória de Pierre Deffontaines". In: Oral history challenges for the 21st century: proceedings [of the] X International Oral History Conference /Eds. Ilana Strozemberg et al. Rio de Janeiro: CPDOC/FGV/Casa Oswaldo Cruz, 1998. v.1. p.379-386.

GUSDORF, Georges. "Condiciones y límites de la autobiografía", em LOUREIRO, Ángel (coord.). 29/Suplementos Anthropos. L'Autobiografía y sus problemas teóricos. Barcelona, Anthropos, 1991.

HEYMANN, Luciana Quillet. "O 'devoir de mémoire' na França contemporânea: entre memória, história, legislação e direitos". In: GOMES, Angela de Castro. Direitos e cidadania memória, política e cultura. Rio de Janeiro: FGV, 2007.

HALBWACHS, M. A memória coletiva. São Paulo: Vértice, 1990.

LE GOFF, J. História e memória. Campinas: Unicamp, 1982.

LEMOS, Renato. "Poder Judiciário e poder militar (1964-69)". In: CASTRO, Celso; IZECKSOHN, Vitor; KRAAY, Hendrik (Orgs.). Nova história militar. Rio de Janeiro: Editora FGV, 2004a. Pp. 409-438.

. Justiça Militar e processo político no Brasil (1964-1968). In: Seminário 40 anos do Golpe de 1964. 1964-2004: 40 anos do golpe: ditadura militar e resistência no Brasil. Rio de Janeiro: 7Letras, 2004b, pp. 282-289.

LORIGA, Sabina. "A tarefa do historiador" (mimeo, 2006).

MACIEL, Wilma Antunes. Repressão judicial no Brasil: o capitão Carlos Lamarca e a VPR na Justiça Militar (1969-1971). Dissertação (Mestrado em História Social) USP, São Paulo, 2003, $184 p$.

MARTINS FILHO, João Roberto. O palácio e a caserna. A dinâmica militar das crises políticas na ditadura (1964-1969). São Carlos: UFSCar, 1995.

MOREIRA, Regina L. "Os diários pessoas e a (re)construção histórica”. Estudos Históricos, Rio de Janeiro, CPDOC/FGV, n. 17, 1996. 
NORA, Pierre. "Entre a memória e a história: a problemática dos lugares". Projeto História, São Paulo, PUC-SP, n. 10, dez. 1993.

. "Memória coletiva” em LE GOFF, J.; CHARTIER, R. e REVEL, J. (Orgs.). A nova história. Coimbra: Almedina, 1990, pp. 451-454.

PEREIRA, Anthony. "Persecution and farce": the origins and transformation of Brazil's political trials, 1964-1979.

. Political (in)justice: authoritarianism and the rule of law in Brazil, Chile and Argentina. Pittsburgh: University of Pittsburgh Press, 2005.

POLLACK, Michael. "Memória, esquecimento, silêncio". Estudos Históricos, Rio de Janeiro, CPDOC/FGV, v. 2, n. 3, 1989.

REMÉDIOS, Maria Luiza Ritzel. "A preservação da vida na escrita: o diário de Getúlio Vargas". Estudos Históricos, Rio de Janeiro, CPDOC/FGV, n. 17, 1996.

RICOEUR, Paul. La mémoire, I'histoire, I'oubli. Paris: Seuil, 2000.

SEIXAS, Jacy Alves. "Halbwachs e a memória-reconstrução do passado: memória coletiva e história". História: revista da Unesp. São Paulo: Ed. Unesp, v. 20, 2001, pp. 93-108.

SILVA, Angela Moreira Domingues da. Ditadura militar e repressão legal: a pena de morte rediviva e o caso Theodomiro Romeiro dos Santos (1969-1971). Programa de Pós-Graduação em História Social (UFRJ), 2007.

SILVA, Hélio. Memória dos vencidos: a vez e a voz dos vencidos. Petrópolis: Vozes, 1988.

TAVARES, FLAVIO. Memórias do esquecimento: os segredos dos porões da ditadura. São Paulo: Globo, 1999. 